\title{
CD64 and CD11b Versus Conventional Bacteriological Methods in Early Detection of Bacterial Neonatal Sepsis
}

\author{
LAILA M. YOUSIF, M.D.*; ABDEL HAMEAD A. MOHAMED, M.D.** and \\ HOSNY M.A. EL-MASRY, M.D.*** \\ The Departments of Clinical Pathology*, Faculty of Medicine, Sohag University, Clinical Pathology** and \\ Pediatrics \& Neonatology***, Faculty of Medicine, Al-Azhar University, Assiut, Egypt
}

\begin{abstract}
Background: Neonatal sepsis is a life-threatening disease that remains a major cause of morbidity and mortality in the newborn. Early recognition and implementation of appropriate therapy offers the best outcome, and careful assessment of the newborn is essential. Early-onset sepsis (EOS) presents a fulminant multi-system illness during the first days of life. Early detection of neonatal sepsis is difficult as the clinical signs are non-specific and indistinguishable from those caused by a variety of neonatal non-infective disorders such as aspiration syndrome and respiratory distress syndrome. An important early event in sepsis is the generation and release of cytokines by immune cells in response to invasion by bacteria and their toxins. Flow cytometry analysis of cell surface antigens (CD64, CD11b, CD32, CD16, CD69, CD25, and $\mathrm{CD} 45$ ) have been performed to detect neonatal sepsis.
\end{abstract}

Aim of Study: To evaluate the usefulness of estimation of neutrophil expression of CD64 and CD1 $1 \mathrm{~b}$ in bacterial neonatal sepsis and to investigate possible relationship between their levels, other markers of sepsis as total leucocytec count (TLC), platelet count and C Reactive protein (CRP), whether levels of expressed CD64 and CD11b correlated with severity of illness, survival or not and to investigate the possible relation between CD64 and CD11b.

Patients and Methods: All Newborns were subjected to complete blood count (CBC), CRP, blood cultures and flowcytometry analysis that had been done for detection of $\mathrm{CD}$ $64, \mathrm{CD} 11 \mathrm{~b}$ on neutrophils.

Results: All prospective study enrolled newborns documented sepsis group $(\mathrm{n}=40)$ and control newborn group $(\mathrm{n}=40)$. It was found that the blood cultures in sepsis group demonstrated the presence of E.coli, KlebsiellaPneumoniae, Staphaureus, Staph Hominis, Staph lentus and Pseudomonas aerogenosa. Also, the mean levels of CD64 and CD11b in sepsis group were significantly higher than that in healthy group $\mathrm{p}$ value is 0.001 . ROC analysis showed that both CD64 and CD1 1b could be used for early detection of sepsis with sensitivity and specificity of more than $97 \%$.

Conclusion: The expression of the neutrophil activation markers CD11b and CD64 could be a reliable tool for early

Correspondence to: Dr. Laila M. Yousif, The Department of Clinical Pathology, Faculty of Medicine, Sohag University prediction and diagnostic of early detection of bacterial neonatal sepsis in the suspected presence neonate, irrespective to otherlaboratory results and before the evolution of clinical signs. Thus, they might indicate the necessity of early initiation of antibiotic treatment for sepsis, with corresponding improvement of the outcome, and reduce the unnecessary use of antimicrobials in non-infected neonates, without waiting for definitive microbiologic results.

Key Words: Neonatal sepsis - Preterm newborns - CD64 CD11 b.

\section{Introduction}

NEONATAL sepsis is life-threatening condition occurring within the first 28 days of life, despite advances in Neonatal care, neonatal sepsis is still a significant cause of morbidity and mortality [1] Bacterial Neonatal Sepsis can be defined as any systemic bacterial infection confirmed by a positive cultures in the first month of life. Up to $10 \%$, infants have infections in the first month of life, the matter that results in $30-50 \%$ of total neonatal deaths in developing countries [2]. EOS is defined by onset in the first week of life, with some studies limiting EOS to infections occurring in the first 72 hours that are caused by maternal intrapartum transmission of invasive organisms [3]. Late-onset sepsis (LOS) is usually defined as infection occurring after 1 week and is attributed to pathogens acquired postnatally. Risk factors for neonatal sepsis include maternal factors, neonatal host factors, and virulence of infecting organism [4] Despite efforts to detect Group B streptococci (GBS) colonization during pregnancy and provide appropriate GBS prophylaxis to colonized mothers, not all cases of early-onset GBS are prevented and GBS continues to be the most common cause of EOS in term neonates. Sepsis caused by E.coli increased in recent years. Together, GBS and E.coli 
account for about $70 \%$ of cases of EOS in the neonatal period [5]. The earliest signs of sepsis often are subtle and nonspecific as poor feeding, diminished activity, or "not looking well" [6] Respiratory distress, apnea, lethargy, fever or hypothermia, jaundice, vomiting, diarrhea and skin manifestations, including petechiae, abscesses and sclerema may be present [7]. The diagnosis of systemic infection in the newborn is difficult. A history of one or more risk factors for neonatal sepsis associated with the pregnancy and delivery often is associated with early-onset infection, but there can be no clues before the onset of subtle signs in a term infant who develops LOS.

Diagnosis of neonatal sepsis is still difficult. The gold standard for detecting bacterial sepsis is blood culture [8]. However, as pathogens in cultures are only detected in approximately $25 \%$ of patients, the sensitivity of blood culture is suspected to be low [9]. These lead to unnecessary exposure to antibiotics before presence of sepsis has been proven with potentially poor outcomes, Clinicians have long sought reliable markers to detect sepsis early in its course and to exclude diseases of noninfectious origin [9]. Flow cytometry analysis of cell surface antigens (CD64, CD11b, CD32, CD16, CD69, CD25, and CD45) has been performed to detect neonatal sepsis [10]. CD64 and CD11b are glycoproteins, known as FC gamma receptor 1 (FC $\gamma \mathrm{R} 1)$, play a coordinating role in immunity and mediates functions such as endocytosis, phagocytosis and cytokine production. CD64 and CD11b are high affinity receptors normally expressed by monocytes and only to a small extent by neutrophils during bacterial infections, the neutrophil expression of CD64 and CD 11b is markedly increased [11].

Aim of this study to evaluate the usefulness of estimation of neutrophil expression of CD64 and $\mathrm{CD} 11 \mathrm{~b}$ in bacterial neonatal sepsis and to investigate possible relationship between their levels, other markers of sepsis as total leucocytec count (TLC), platelet count and C Reactive protein (CRP), to determine whether levels of expressed CD64 and CD $11 \mathrm{~b}$ correlated with severity of illness, survival or not and to investigate the possible relation between CD64 and CD11b.

\section{Patients and Methods}

\section{Study design and patients:}

This cross sectional study conducted over the period from January 2016 to September 2016 at neonatal intensive care unit (NICU) of Al-Azhar
Assiut University Hospital and Sohag University Hospital (40 with bacterial sepsis and 40 apparent healthy neonates as controls).

Inclusion criteria: Newborns with bacterial sepsis provided by risk factors and laboratory work up irrespective to postnatal age (either cultures positive or cultures negative).

Exclusion criteria: Newborns with sepsis other than bacterial and those with congenital anomalies, malignancy, hypoxic ischemic encephalopsy Pathological jaundice ( $\mathrm{RH}$ or $\mathrm{ABO}$ incompatibility) or pallorfor any reason as cephalohematoma were excluded from our study.

\section{Newborns were subjected to the following:}

- Full clinical history including personal history as age, sex, present history with emphasis on date of onset, precipitating factors, course and duration of the disease and presence or absence of symptoms suggestive of sepsis and prenatal, maternal and obstetric history.

- Examination include, the resuscitation need, need for incubation care, gestational age assessment and clinical diagnosis of sepsis.

- Chest and abdominal X-ray if indicated [9]

- Laboratory Investigations.

Complete blood count $\mathrm{CBC}$ on an automated cell counter (SysmexX-2000i series, CD64 and CD11 expressionusing BD FACSCalibur flow cytometer (Paraskevas et al., 2004). C-reactiveprotein (CRP) detection by semi quantitative measurement by ATLAS combridge, cb4 owx UK (Mishra et al., 2006).

Blood cultureusing blood culture bottles (BACT/ALERT SA BIOMERIEUX, INC DURH$\mathrm{AM}, \mathrm{NC27704)}$ was performed for all patients then incubated at $37^{\circ} \mathrm{C}$ for up to 7 days; Subculture was done on blood agar, chocolate agar and MacConkey's agar and identification of bacteria using VITEK 2 automated microbiology system.

Sepsis in newborn is proved by the following laboratory indicators: Immature neutrophil increase, neutrophilia (neutrophil count $>9000 / \mathrm{ul}$, Thrombocytopenia (platelet count $<100.000 / \mathrm{ul}$, ESR $>15, \mathrm{CRP}>6 \mathrm{mg} / \mathrm{L}$ and positive cultures.

All control neonates show no sign of sepsis since birth till the time of sampling. 
Statistical analysis:

- Statistical package for social sciences (IBMSPSS), version 24 IBMnm-/. Chicago, USA was used for statistical data analysis.

- Data expressed as mean, standard deviation (SD), number and percentage. Mean and standard deviation were used as descriptive value for quantitative data, while number and percentage were used to describe qualitative data.

- Student $t$ test was used to compare the means between two groups. Mann Whitney test was used in stead of Student $t$-test in case of non parametric data.

- Pearson Chi square was used to compare percentages of qualitative data, and Fisher's Exact test was used for non parametric data.

- Pearson correlation test was used to compare two quantitative variables. The value of $(r)$ is explained in the following figures:

- $r<0.2 \rightarrow$ negligible correlation.

- $r$ 0.2-0.4 $\rightarrow$ weak correlation.

- $r$ 0.4-0.7 $\rightarrow$ moderate correlation.

- $r$ 0.7-1 $\rightarrow$ strong correlation.

- $r$ positive $\rightarrow$ positive correlation.

- $r$ negative $\rightarrow$ negative correlation.

- For all these tests, the level of significance ( $p$ value) can be explained as:

- No significance $p>0.05$

- Significance $p<0.05$

- High significance $p<0.001$.

\section{Results}

The study includes 40 neonates with sepsis group ( 23 males and 17 females); their ages Mean $\pm \mathrm{SD}(13.83 \pm 7.11)$ and 40 neonates not complain from sepsis as control group (25 males and 15 females) their age Mean \pm SD $(12.13 \pm 6.1)$. The difference in age and gender was non-significant. Also, we found that the mean birth weight in sepsis group was $(2876 \pm 1077 \mathrm{gm})$ that is lower than in control group ( $3290 \pm 671 \mathrm{gm})$ and this difference was statistically significant $(p$-value $=0.001)$.

As regard history of PROM, only 4 babies had PROM ( 3 were from sepsis group, 1 from healthy group). This difference was non-significant ( $p$ value $=0.615$ ), and regarding to gestational age in sepsis group 21 cases $(52.5 \%)$ were preterm and 19 cases $(47.5 \%)$ were term and 10 cases $(25 \%)$ preterm in control group and 30 cases $(75 \%)$ and this difference was statistically significant ( $p$-value $=0.03$ ).
Regarding the laboratory analysis of the two groups of our study, our results are as shown in Table (1) CBC show significant decrease hemoglobin and platelets in sepsis group than control group $p$-value $(<0.001)$ and significant increase WBCs in sepsis group than control group $p$-value $(<0.001)$. While CRP was positive with among sepsis group, with a Mean \pm SD (128.90 \pm $68.41 \mathrm{mg} / \mathrm{l}$ ) but it was negative among all control group, Blood culture was positive in $92.5 \%$ of sepsis group (37 cases out of 40) but was negative in all of the 40 controls.

Table (1): Comparison of the demographic, clinical, and laboratory data among studied groups.

\begin{tabular}{|c|c|c|c|}
\hline Characteristics & $\begin{array}{c}\text { Cases group } \\
\mathrm{N}=40\end{array}$ & $\begin{array}{c}\text { Control group } \\
n=40\end{array}$ & $\begin{array}{c}p- \\
\text { value }\end{array}$ \\
\hline \multicolumn{4}{|l|}{ Age group: } \\
\hline 0-7 days & $11(27.5 \%)$ & $26(65 \%)$ & \multirow[t]{2}{*}{0.254} \\
\hline$>7$ days & $29(72.5 \%)$ & $14(35 \%)$ & \\
\hline \multicolumn{4}{|l|}{ Sex: } \\
\hline Male & $23(57.5 \%)$ & $25(62.5 \%)$ & \multirow[t]{2}{*}{1} \\
\hline Female & $17(42.5)$ & $15(27.5 \%)$ & \\
\hline \multicolumn{4}{|l|}{ Birth weight ( $\mathrm{kg})$ : } \\
\hline$>2.5$ & $22(55 \%)$ & $35(87.5 \%)$ & \multirow[t]{2}{*}{0.001} \\
\hline $1-2.5$ & $18(45 \%)$ & $5(12.5 \%)$ & \\
\hline \multicolumn{4}{|l|}{ Gestationalage: } \\
\hline Preterm <37 weeks & $21(52.5 \%)$ & $10(25 \%)$ & \\
\hline Term $\geq 37$ weeks & $19(47.5 \%)$ & $30(75 \%)$ & \\
\hline \multicolumn{4}{|l|}{ PROM: } \\
\hline Yes & $3(7.5 \%)$ & $1(2.5 \%)$ & \multirow[t]{2}{*}{0.615} \\
\hline No & $37(92.5 \%)$ & $39(97.5 \%)$ & \\
\hline \multicolumn{4}{|l|}{$C B C$ : } \\
\hline $\mathrm{HB}(\mathrm{gml})$ & $11.83 \pm 2.81$ & $13.92 \pm 1.50$ & $<0.001$ \\
\hline Platelets (x10 /ul) & $55.20 \pm 38.48$ & $291.80 \pm 84.34$ & $<0.001$ \\
\hline Total WB Cs $\times 10^{3} / \mathrm{ul}$ & $20.22 \pm 7.77$ & $10.76 \pm 3.01$ & $<0.001$ \\
\hline Neutrophil (\%) & $64.03 \pm 5.13$ & $40.95 \pm 6.80$ & $<0.001$ \\
\hline Band $\quad(\%)$ & $16.90 \pm 2.24$ & $3.75 \pm 4.04$ & $<0.001$ \\
\hline Lymphocyte (\%) & $16.5 \pm 6.08$ & $52.25 \pm 8.00$ & $<0.001$ \\
\hline $\mathrm{CRP}(\mathrm{mg} / \mathrm{dl})$ & $128.90 \pm 68.41$ & 0 & $<0.001$ \\
\hline \multicolumn{4}{|l|}{ Blood culture: } \\
\hline Positive & $37(92.5 \%)$ & 0 & \multirow[t]{2}{*}{$<0.001$} \\
\hline Negative & $3(7.5 \%)$ & $40(100 \%)$ & \\
\hline CD64 & $95.54 \pm 9.43$ & $14.5 \pm 7.5$ & $<0.001$ \\
\hline CD11b & $86.04 \pm 11.58$ & $15.43 \pm 10.9$ & $<0.001$ \\
\hline
\end{tabular}

Regarding the onset of sepsis, we found that a little more than quarter of sepsis 11 cases $(27.5 \%)$ had early onset sepsis, where the remaining 29 cases $(72.5 \%)$ had late onset sepsis. Following the outcome of the sepsis group we found that 5 babies 
died from sepsis group. When we compare this fatality rate $(12.5 \%)$ with the zero mortality among control group, the difference was significant ( $p$ value $=0.021$ ).

Our study show that the mean level of CD64 in sepsis group was much higher (95.54 \pm 9.44$)$ than that of control group $(14.51 \pm 7.51)$ and this difference was highly significant ( $p$-value $<0.001$ ). The mean $\mathrm{CD} 11 \mathrm{~b}$ level was also higher among sepsis group (86.04 \pm 11.58$)$ than that in healthy group $(15.43 \pm 10.9)$ and this difference was highly significant ( $p$-value $<0.001)$.

We found that the most commonly isolated organism was E.coli, seen in 17 cases, followed by Klebsiella pneumonia (seen in 10 cases). Staphylococci were isolated in 8 cases (Staph. aureus in 3 cases, hominis in 3 cases and lentus in 2 cases). Pseudomonas aerogenosa was isolated in only 2 cases. In 3 cases, no organism could be isolated. There is no significant difference between the onset of sepsis and the type of organism isolated (Table 2).
Studying the correlation between CD64 and $\mathrm{CD} 11 \mathrm{~b}$, we found that there is strong, positive and highly significant correlations between CD64 and CD11b, which mean that the two CDs are highly related to each other (Fig. 1). Comparison between the blood culture positive cases ( 37 cases) with the blood culture negative cases ( 3 cases) as regards $\mathrm{CBC}$, we found that there is non-significant difference between the two groups (Table 3).

Putting the values of CD64 and CD11b in a ROC curve model to assess if any of them can be used as a predictive marker of sepsis we found that both of CD64 and CD11b can be used to differentiate sepsis cases from healthy controls both had a highly significant $p$-value. Using coordinate points of the above ROC curve, the most relevant cut off point for CD64 to differentiate cases from controls is 47.15 , with a sensitivity of $97.5 \%$, and a specificity of $100 \%$. In addition, the most relevant cut off point for CD $11 \mathrm{~b}$ is 51 , with a sensitivity of $100 \%$, and a specificity of $97.5 \%$ in Table (4).

Table (2): Isolated organisms among early and late onset sepsis patients.

\begin{tabular}{|c|c|c|c|c|c|c|}
\hline \multirow[b]{2}{*}{ Type } & \multicolumn{2}{|c|}{ EOS } & \multicolumn{2}{|c|}{ LOS } & \multirow[b]{2}{*}{$\begin{array}{c}\text { Chi } \\
\text { square }\end{array}$} & \multirow[b]{2}{*}{$p$-value } \\
\hline & $\begin{array}{c}\text { No. } \\
11\end{array}$ & $\begin{array}{c}\% \\
27.5\end{array}$ & $\begin{array}{c}\text { No. } \\
29\end{array}$ & $\begin{array}{c}\% \\
72.5\end{array}$ & & \\
\hline Escherichia coli & 3 & 27.3 & 14 & 48.3 & 1.440 & 0.230 \\
\hline Klebsiella pneumonia & 4 & 36.4 & 6 & 20.7 & 1.045 & 0.307 \\
\hline Staph. Aureus & 0 & 0 & 3 & 10.3 & 1.230 & 0.267 \\
\hline Staph. Hominis & 1 & 9.1 & 2 & 6.9 & 0.055 & 0.815 \\
\hline Staph. Lentus & 1 & 9.1 & 1 & 3.4 & 0.535 & 0.465 \\
\hline Pseudomonas aerogenosa & 0 & 0 & 2 & 6.9 & 0.799 & 0.371 \\
\hline No growth & 2 & 18.2 & 1 & 3.4 & 2.495 & 0.114 \\
\hline
\end{tabular}

Table (3): CBC, CD64, CD11 and CRP versus blood culture among sepsis cases.

\begin{tabular}{lllll}
\hline & $\begin{array}{c}\text { Blood culture } \\
\text { positive } \\
(37 \text { cases })\end{array}$ & $\begin{array}{c}\text { Blood culture } \\
\text { negative } \\
(3 \text { cases })\end{array}$ & $t$-test & $p$-value \\
\hline CD64 Mean \pm SD & $95.42 \pm 9.76$ & $97.07 \pm 4.14$ & 0.287 & 0.001 \\
CD11b Mean \pm SD & $87.22 \pm 10.23$ & $71.5 \pm 19.75$ & 1.363 & 0.001 \\
CRP Mean \pm SD $(\mathrm{mg} / \mathrm{l})$ & $127.68 \pm 68.30$ & $144 \pm 83.14$ & 0.393 & 0.03 \\
PLT Mean \pm SD $(x 10 \% / \mathrm{ul})$ & $56.03 \pm 39.63$ & $45 \pm 21$ & 0.473 & 0.003 \\
Band Mean $\pm \mathrm{SD}(\%)$ & $17 \pm 2.17$ & $15.67 \pm 3.22$ & 0.992 & 0.001 \\
Lymphocyte Mean $\pm \mathrm{SD}(\%)$ & $16.41 \pm 5.95$ & $17.67 \pm 8.96$ & 0.342 & 0.734 \\
\hline
\end{tabular}

Table (4): Comparison of AUC Values, sensitivity, specificity, PPV, NPV from ROC curves between clinical sepsis and control group.

\begin{tabular}{lccccccc}
\hline Variable & Area & $p$-value & Cut off values & Sensitivity & Specificity & PPV & NPV \\
\hline CD64 & 0.964 & $<0.001$ & 47.15 & $97.5 \%$ & $100 \%$ & 97 & 98 \\
CD 11 & 0.986 & $<0.001$ & 51 & $97.3 \%$ & $97.7 \%$ & 97.5 & 97 \\
\hline
\end{tabular}




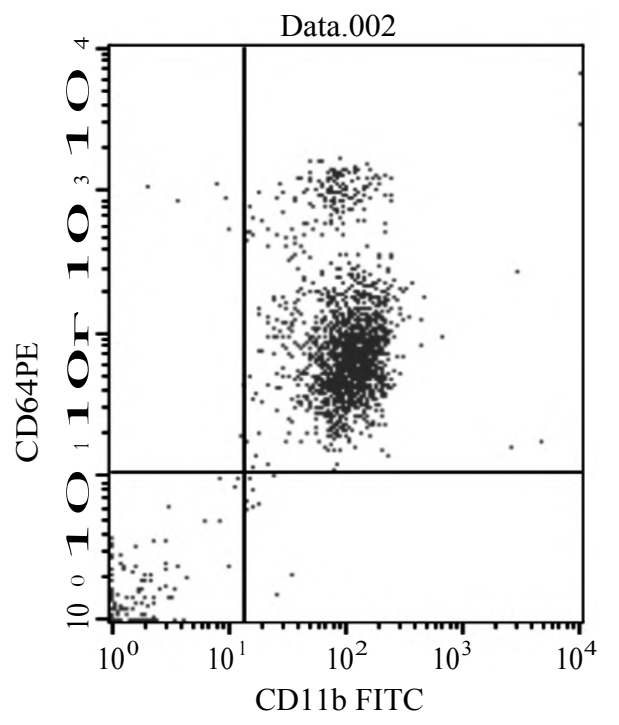

Fig. (1A): Flowcytometry diagram showing positive for CD64 and CD11b.

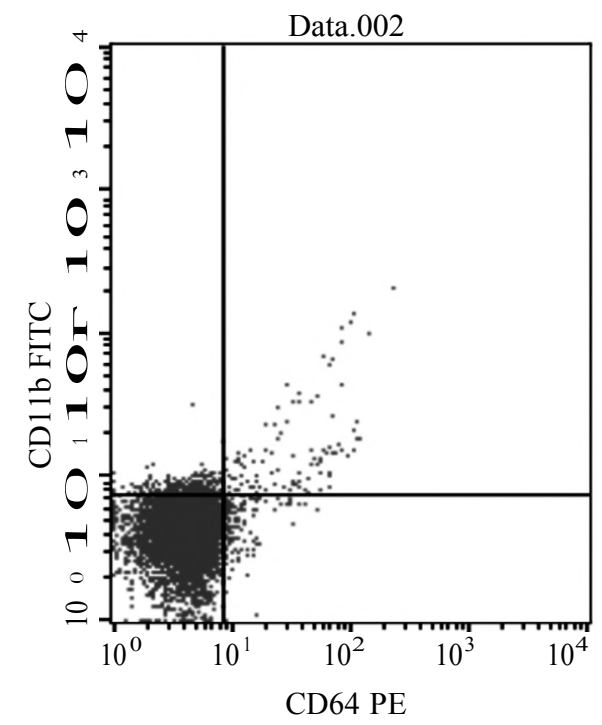

Fig. (2A): Flowcytometry diagram showing negative for CD64 and $\mathrm{CD} 11 \mathrm{~b}$

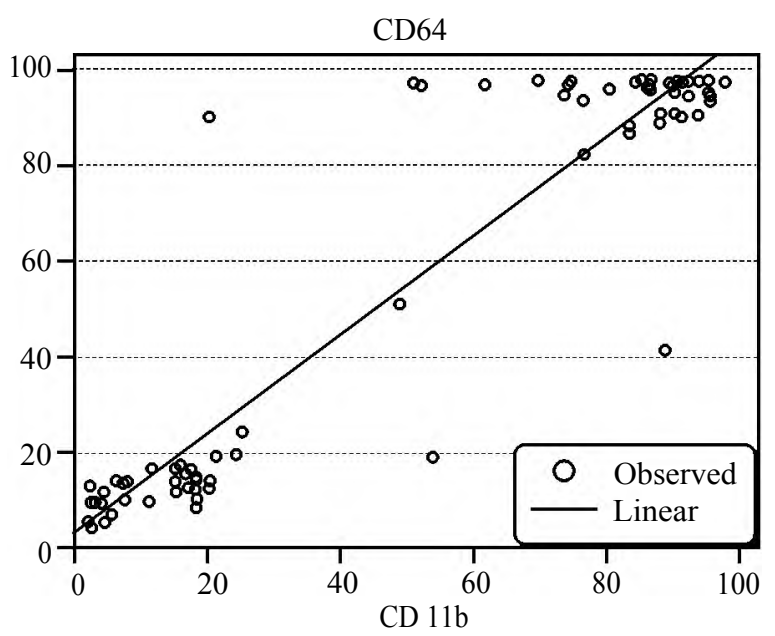

Fig. (3): Correlation between CD64 and CD11b (Pearson Correlation test $(r): 0.951, p$-value: $<0.001)$.

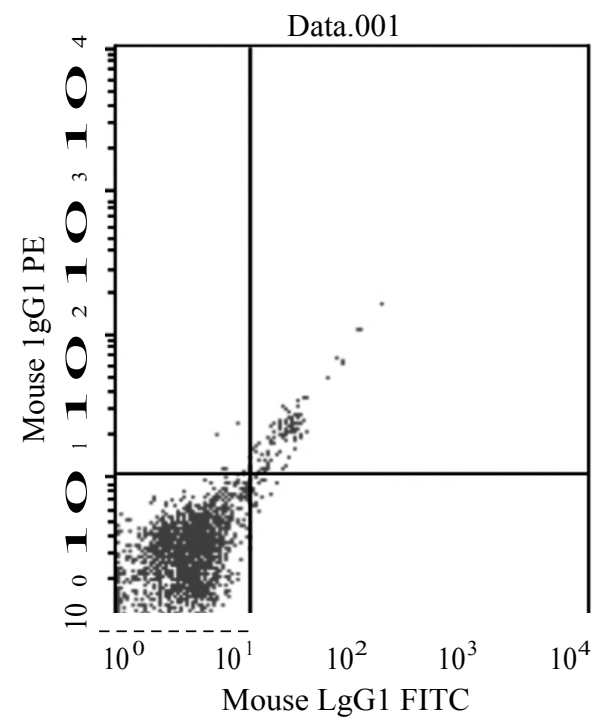

Fig. (1B): Flowcytometry diagram showing control of the sample of the same patient.

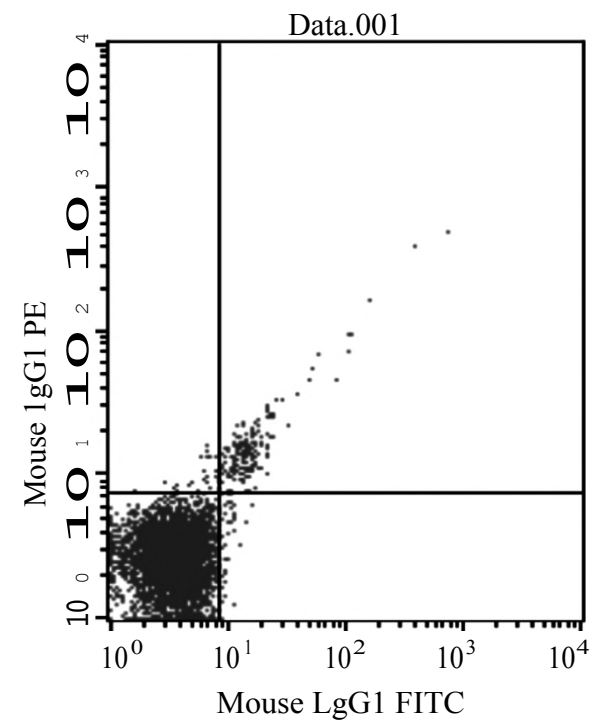

Fig. (2B): Flowcytometry diagram showing control of the sample of the same patient.

\section{Discussion}

Neonatal sepsis is a life-threatening disease that remains a major cause of morbidity and mortality in the newborn, mainly among preterm and low birth weight (LBW) infants [13]. Early recognition and implementation of appropriate therapy offers the best outcome, and careful assessment of the newborn is essential [14]. EOS occurs in newborn infants with one or more obstetric complication including PROM [14], premature onset of labor [15], chorioamnionitis, or peripartum maternal fever [16]. Early detection of neonatal sepsis is difficult as the clinical signs are non-specific andindistinguishable from those caused by a variety of neonatal non-infective disorders such as aspiration syndrome and respiratory distress syndrome. It is therefore 
recommended for all neonates who develop these signs to start empirical antimicrobial therapy [17] An important early event in sepsis is the generation and release of cytokines by immune cells in response to invasion by bacteria and their toxins [18] These cytokines induce activation of leucocytes [10]. During neutrophil activation, surface adhesion molecules including L-selectin [19], CD43, CD44 [20] and CD50 [21] areexpressed and cleaved from neutrophil cell surface [22]. In contrast, the leucocyte integrin Mac-1 (CD11b/CD18) and the high affinity Fc $\gamma$ receptor I (CD64) behave as activation antigens on neutrophils, increasing their expression on the surface of the cell after its activation and hence, are considered as specific neutrophil-surface activation markers [20]. Activation of CD11b and CD64 surface antigens expression had been shown by neonatal neutrophils to an extent similar to those of older children and adults, thus they could potentially be used for identification of neonatal life-threatening infections [23]

Rapid diagnosis of sepsis is problematic because the first signs of this disease may be minimal; furthermore, cultures is golden method for detection and identification of type of organisms and it is sensitivity, bacterial cultures are time consuming, other laboratory tests are either not available for routine use or lack sensitivity or specificity. In this situation, neonates with risk factors for infection or clinical suspicion of infection are empirically treated with antibiotics. In our study, mean of age in sepsis group was (13 days) that is more than healthy group (12 days). This was similar to studies by $\mathrm{Ng}$ et al., [24] and Khassawneh et al., [25] as mean age was $12.54 \pm 7.17$ days in sepsis group and mean age was $13.80 \pm 7.46$ days in healthy group. In addition, in our study number of male and female patients was equal in both groups, this was closly similar to that reported by Hodge et al., [10] as in their study male: Female were 60\%: $40 \%$. We reported that CRP was very higher in sepsis group than healthy group which was less than $6 \mathrm{mg} / \mathrm{l}$, also mean number of PLT, Lymphocytes and HB was lower in sepsis group, also mean of number of neutrophil, WBCs and BAND was higher in sepsis groupthan that in healthy group. This confim results done by Livaditi et al., [26], Groselj-Grenc et al., [27] as they reported significant differences in some laboratory data, the platelet count was significantly lower $(p=0.001)$ and WBCs $(p=0.01)$ and CRP were significantly higher $(p=0.001)$ in patients group. In our study, most of the blood cultures in sepsis group demonstrated (37 cases) culture positive $(92.5 \%)$, the presence of E.coli (17 cases), Klebsiellapneumoniae (10 cases), staph aureus (3 cases), staph hominis ( 3 cases), staph lentus ( 2 cases) and pseudomonas aerogenosa ( 2 cases), this percent is higher than usual, may be, due to five cases more likely to be contaminanted by (staph hominis 3 cases and staph lentus 2 cases). Stoll et al., [15] found positive blood cultures for bacteria encountered in $22(75.8 \%)$ of cases.

We found that number of premature babies was equal in both groups, majority of babies in sepsis group improved $(87.5 \%)$, only 4 babies had PROM (3 were from sepsis group, 1 from healthy group, also mean weight was higher in healthy group than sepsis group. This confirmed results done by Fujimi et al., [28], Elghetany et al., [29] as they found significantly lower mean birth weight $(p<0.05)$ in septic group as compared to the non-septic group. In our study, mean CD64 in sepsis group was higher than that in healthy group. Rebuck et al., [30] found mean percentage of neutrophil CD64 expression did not show significant difference between sepsis and non infection groups in initial samples obtained from cord blood $(p>0.05)$. Progressive significant increases in mean CD64 expression in sepsis group in comparison to noninfected neonates, were observed in subsequent blood samples obtained at 8 and $24 \mathrm{hr}$, and peaked at $48 \mathrm{hr}(p<0.001$, respectively), also we found mean of CD11b was higher in sepsis group than that in healthy group, there is strong and highly significant correlations between CD64 and CD11b. This confirm results reported by Livadili et al., [26], Groselj-Grenc et al., [27] as they found levels of both CD64 and IL6 were significantly higher in cases than controls $(p=0.001)$. Another group of investigators found that CD64 expression was elevated in most survivors and non-survivors of septic shock as compared to non-septic adult patients [31]. Weirich et al., [32] and Nupponen et al., [33] found an increased expression of CD11b in neonatal sepsis that seemed superior to CRP in the detection of inflammation at its early stage. The same findings were also confirmed by El-Kerdaniet al., [34] and Khazbak et al., [35] who suggested that $\mathrm{CD} 11 \mathrm{~b}$ is normally expressed at a low level on the surface of neonatal non-activated neutrophils. Its expression on neutrophil cell surface, however, increases substantially within a few minutes after the cell comes in contact with bacteria or endotoxins thus it could be superior to CRP and the hematological scoring system in the early detection of neonatal sepsis. Davis and Bigelow [36], Nuutilaet al., [27] and Rudensky et al., [38] reported that neutrophil CD64 expression is an improved diagnostic indicator of sepsis. The results of our study are in line with this as we found significantly elevated levels of CD64 in septic neonates when compared to healthy controls. These findings are 
also in agreement with other studies Shao et al., [39] and $\mathrm{Ng}$ et al., [40] which reported the same results in neonate's with EOS. With compare the results of CD64 and CD11b is positivein bacterial neonatal sepsis and negative with other neonatal conditions as bowel obstruction in the newborn, congestive heart failure ...etc. In our study, ROC analysis showed that both CD64 and CD11b could be used for early detection of sepsis with sensitivity and specificity of more than $97 \%$. Also, ROC analysis showed that both CD64 and Cd1 1b could be used for prediction of positive blood culture patients with sensitivities of more than $97 \%$ and specificities of $93 \%$ and $98 \%$; respectively.

\section{Conclusion:}

The expression of the neutrophil activation markers CD11b \& CD64 could be a reliable tool for early prediction and diagnostic of early detection of bacterial neonatal sepsis in the suspected neonate, irrespective to other laboratory results and before the evolution of clinical signs. Thus, they might indicate the necessity of early initiation of antibiotic treatment for sepsis, with corresponding improvement of the outcome, and reduce the unnecessary use of antimicrobials in non-infected neonates, without waiting for definitive microbiologic results.

\section{References}

1- SHIM G.H., S.D. KIM, S.H. KIM and E.H. CHOI: Trend in epidemiology of neonatal sepsis in a centre in korea. J. Korean. Med. Sci., 26: 284-9, 2011.

2- SHAHSANAM G., ZAHRA F., MOHAMMAD K., JAVAD K., BEHROOZ I., FARZIN A., et al.: Coagulase negative staphylococcus; the most common cause of neonatal septicemia in Urmia, Iran, Iran J. Pediatr., 18: 237-43, 2008.

3- VERANI J.R., MCGEE L. and SCHRAG S.J.: Division of Bacterial Diseases NCfI, Respiratory Diseases CfDC, Prevention. Prevention of perinatal group B streptococcal disease-revised guidelines from CDC, 2010. MMWR Recommendations and reports: Morbidity and mortality weekly report Recommendations and Reports, 59 (RR10): 1-36, 2010.

4- STOLL B.J., HANSEN N.I. and SANCHEZ P.J.: Early onset neonatal sepsis: The burden of group B Streptococcal and E. coli disease continues. Pediatrics, 127: 817-26, 2011.

5- VERGNANO S., SHARLAND M., KAZEMBE P., MWANSAMBO C. and HEATH P.T.: Neonatal sepsis: An international perspective. ArchDis Child. Fetal. Neonatal. Ed., 90: 220-4, 2011.

6- KERMORVANT-DUCHEMIN.: Outcome and prognostic factors in neonates with septic shock, Pediatr. Crit. Care. Med., 9: 186-91, 2008.

7- KUDAWLA M., S. DUTTA and A. NARANG.: Validation of a clinical score for the diagnosis of late onset neonatal septicemia in babies weighing 1000-2500g, J. Trop. Pediatr., 54: 66-9, 2008.

8- WEINBERG G., ANGIO C.D. and C. WILSON: Infectious diseases of the Fetus and Newborn ( $6^{\text {th }}$ Ed): 1207-22, 2006.

9- ARNON R.: Diagnostic tests in neonatal sepsis curr opin infect Dis., 21: 223-7, 2008.

10- HODGE G., HADGE S., HASLAM R. and ZOLA H.: Rapid simultaneous measurement of multiple cytokines using 100 microl sample volumes association with neonatal sepsis. Clin. Exp. Immunol., 137: 402-7, 2004.

11- GENEL F., F. AATLIHAN, N. GULE and E. KAZANCI: Evaluation of adhesion molecules CD64 CD11b and CD 62 in neutrophils and monocytes of peripheral blood for early diagnosis of neonatal infection World Pediatric, 8: 72-5, 2011.

12- MISHRA U.K., JACOBS S.E. and DOYLE L.W.: Newer approaches to the diagnosis of early onset neonatal sepsis. Arch. Dis. Child. Fetal. Neonatal. Ed., 91: F208-12, 2006.

13- GUERINA N.G.: Bacterial and fungal infection. In: Cloherty J.P., Stark A.R., editors. Manual of neonatal care. Philadelphia: Lippincott Raven, 271-300, 1998.

14- PUOPOLO K.M., MUKHOPADHYAY S., HANSEN N.I., et al.: NICHD Neonatal Research Network. Identification of extremely premature infants at low risk for early-onset sepsis. Pediatrics. doi: 10.1542/peds, 0925, 2017.

15- STOLL B.J.: Infections of the neonatal infant: Epidemiology of early and late-onset neonatal infections. In: Behrman R.E., Kliegman R.M., Jenson H.B., editors. Nelson textbook of pediatrics. 17 th ed. Philadelphia: W.B. Saunders, 627-30, 2004.

16- CHEN K.T., RINGER S., COHEN A.P. and LIEBERMAN E.: The role of intrapartumfever in identifying asymptomatic term neonates with early-onset neonatal sepsis. J. Perinatol., 22 (8): 653-7, 2002.

17- LOTT J.W.: Neonatal bacterial sepsis. Crit. Care. Nurs. Clin. North. Am., 15 (1): 35-46, 2003.

18- BERNER R., NIEMEYER C.M., LEITITIS J.U., FUNKE A., SCHWAB C., RAU U., et al.: Plasma levels and gene expression of granulocyte colony-stimulating factor, tumor necrosis factor-alpha, interleukin (IL)-1 beta, IL-6, IL8 and soluble intercellular adhesion molecule- 1 in neonatal early onset sepsis. Pediatr. Res., 44 (4): 469-77, 1998.

19- GONZALEZ-AMARO R. and SANCHEZ-MADRID F.: Cell adhesion molecules: Selectins and integrins. Crit. Rev. Immunol., 19 (5-6): 389-429, 1999.

20- GONZALEZ-AMARO R., DIAZ-GONZALEZ F. and SA- NCHEZ-MADRID F.: Adhesion molecules in inflammatory diseases. Drugs., 56 (6): 977-88, 1998.

21- DEL POZO M.A., PULIDO R., MUNOZ C., ALVAREZ V., HUMBRIA A., CAMPANERO M.R., et al.: Regulation of ICAM-3 (CD50) membrane expression on human neutrophils through a proteolytic shedding mechanism. Eur. J. Immunol., 24 (11): 2586-94, 1994.

22- BAZIL V.: Physiological enzymatic cleavage of leukocyte membrane molecules. Immunol. Today, 16 (3): 135-40, 1995. 
23- WEINSCHENK N.P., FARINA A. and BIANCHI D.W.: Premature infants respond to early-onset and late-onset sepsis with leukocyte activation. J. Pediatr., 137 (3): 34550, 2000.

24- NG P.C. and LAM H.S.: Diagnostic markers for neonatalsepsis. Curr. Opin. Pediatr., 18: 125 -31, 2006.

25- KHASSAWNEH M., HAYAJNEH W.A., KOFAHI H., KHADER Y. and AMARIN Z. and DAOUD A.: Diagnostic markers for neonatal sepsis: Comparing C-reactive protein, interleukin-6 and immunoglobulin M. Scand J. Immunol., 65: $171-5,2007$.

26- JIDAI, WENJIE JIANG, ZHIGANG MIN, JIAN YANG, YONGFEI TAN, TIELIANG MA and ZHIJUN GE: Neutrophil CD64 as a diagnostic marker for neonatal sepsis: Meta-analysis. Adv. Clin. Exp. Med., 26 (2): 327-332, 2017.

27- GROSELJ-GRENC M., IHAN A. and DERGANC M.: Neutrophil and monocyte CD64 and CD163expression in critically ill neonates and children withsepsis: Comparison of fluorescence intensities and calculated indexes. Mediators Inflamm, 2026-46, 2008.

28- FUJIMI S., OGURA H., TANAKA H., KOH T., HOSOTSUBO H., NAKAMORI Y., et al.: Activated polymorphonuclear leukocytes enhance production of leukocyte microparticles with increased adhesion molecules in patients with sepsis. J. Trauma., 52 (3): 443-8, 2002.

29- ELGHETANY M.T. and LACOMBE F.: Physiologic variations in granulocytic surface antigen expression: impact of age, gender, pregnancy, race, and stress. J. Leukoc. Biol., 75 (2): 157-62, 2004.

30- REBUCK N., GIBSON A. and FINN A.: Neutrophil adhesion molecules in term and premature infants: Normal or enhanced leucocyte integrins but defective L-selectin expression and shedding. Clin. ExpImmunol., 101 (1): 183-9, 1995.

31- FISCHER G., SCHNEIDER E.M., MOLDAWER L.L., KARCHER C., BARTH E., SUGER-WIEDECK H., et al.: CD64 surface expression on neutrophils is transiently upregulated in patients with septic shock. Intensive Care. Med., 27 (12): 1848-52, 2001.

32- WEIRICH E., RABIN R.L., MALDONADO Y., BENITZ W., MODLER S. and HERZENBERG L.A.: Neutrophil
CD11b expression as a diagnostic marker for early-onset neonatal infection. J. Pediatr., 132 (3 Pt 1): 445-51, 1998.

33- NUPPONEN I., ANDERSSON S., JARVENPAA A.L., KAUTIAINEN H. and REPO H.: Neutrophil CD11b expression and circulating interleukin- 8 as diagnostic markers for early-onset neonatal sepsis. Pediatrics, 108 (1): E12-7, 2001.

34- EL-KERDANI T.A., ABD EL-WAHED M.A., ALI G.S., ABD EL-BASSET F.Z. and EL-BARBARY M.N.: The value of the neutrophil CD1 $1 \mathrm{~b}$ expression, interleukin-6 and soluble receptor of tumor necrosis factor in early diagnosis of neonatal sepsis. Egypt J. Neonatol., 2 (2): 115-25, 2001

35- KHAZBAK M.A., IMAM S.S., ABD EL-KHALIK H. and MOHAMED M.H.: T-cell activation markers CD45RO and CD45RA, neutrophil CD11b expression and soluble tumor necrosis factor receptor (P55) in early diagnosis of neonatal sepsis. Egypt J. Pediatr. Allergy Immunol., 1 (2): 110-7, 2003.

36- DAVIS B.H. and BIGELOW N.C.: Comparison of neutrophil CD64 expression, manual myeloid immaturity counts, and automated hematology analyzer flags as indicators of infection or sepsis. Lab. Hematol., 11 (2): 137-47, 2005.

37- NUUTILA J., HOHENTHAL U., LAITINEN I., KOTILAINEN P., RAJAMÄKI A., NIKOSKELAINEN J., et al.: Simultaneous quantitative analysis of Fc gamma RI (CD64) expression on neutrophils and monocytes: a new, improved way to detect infections. J. Immunol. Methods, 328 (1-2): 189-200, 2007.

38- RUDENSKY B., SIROTA G., ERLICHMAN M., YINNON A.M. and SCHLESINGER Y.: Neutrophil CD64 expression as a diagnostic marker of bacterial infection in febrile children presenting to a hospital emergency department. Pediatr. Emerg. Care., 24 (11): 745-8, 2008.

39- SHAO J., HUANG X.W., SUN M.Y., DU L.Z., TANG, Y.M. and LE Y.L.: Expression of peripheral blood neutrophil CD64 in neonatal septicemia. Zhonghua Er Ke Za Zhi, 43 (7): 510-3, 2005.

40- NG P.C.: Diagnostic markers of infection in neonates. Arch. Dis. Child. Fetal. Neonatal. Ed., 89 (3): F229-35, 2004. 


\section{سى دى\&7 وسى دى الب مقارنة بالطرق البكتيرية التقليدية البيدية

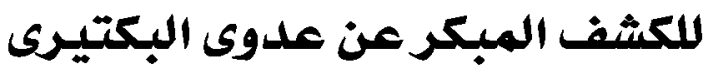 لحلديثى الولادة}

مقدمة: يعتبر تسمم الدم البكتيرى في الأطفال حديثى الولادة من الأسباب الرئيسية للمرض والوفيات. وعلى الرغم من التمات التقدم الكبير

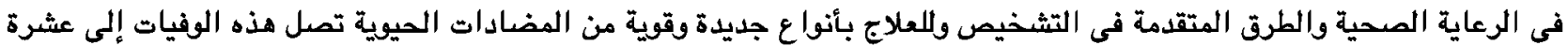

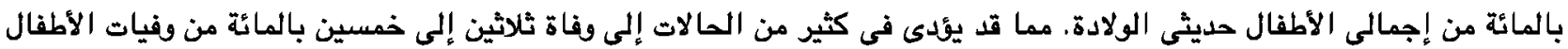

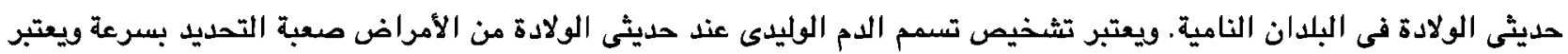

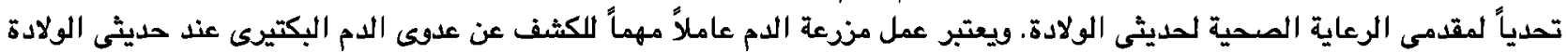

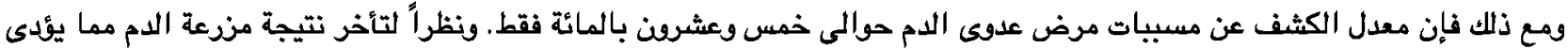

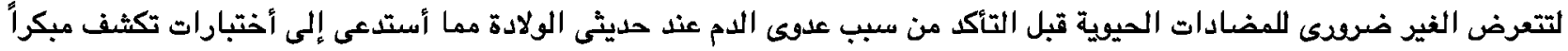

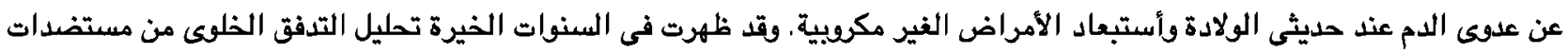

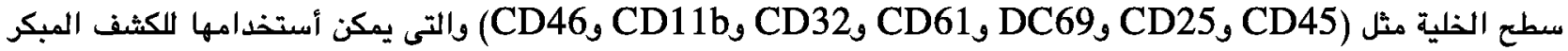

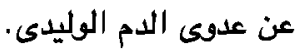

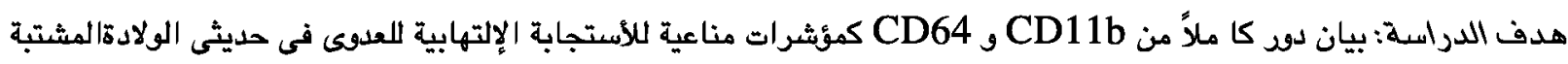

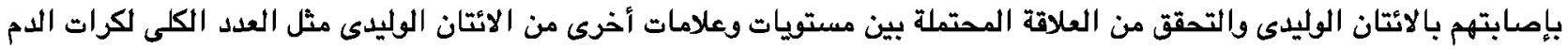

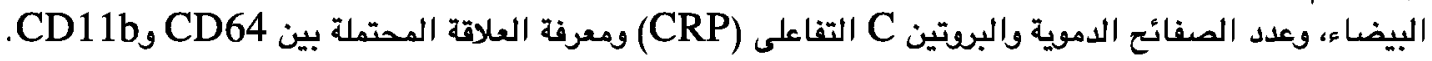

المرضى وطرق البحت: فى هذه الدراسة تم إخضاع حديثى الولادة المصابين بالائتان الوليدى و المجموعة الضابطة إلى العدد

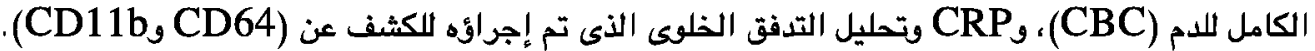

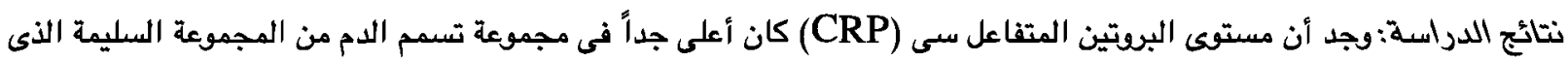

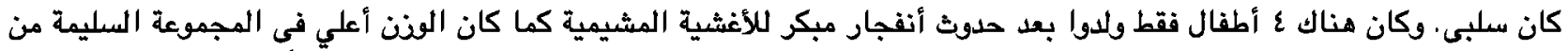

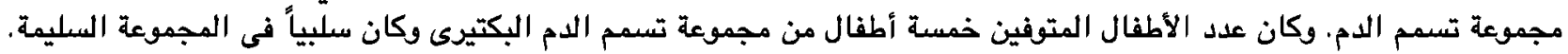

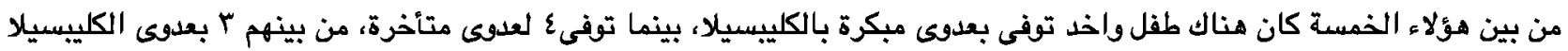

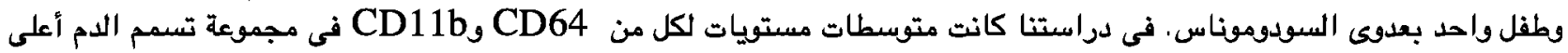
بكثير من تلك التى في المجموعة السليمة. وقد أظهر تحليل ROC أن كلا من

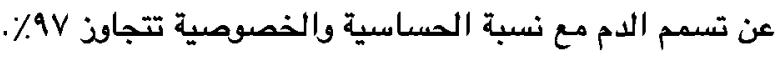

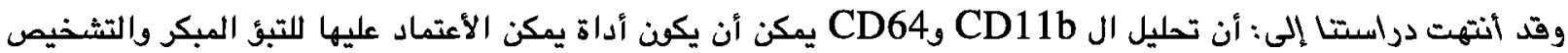

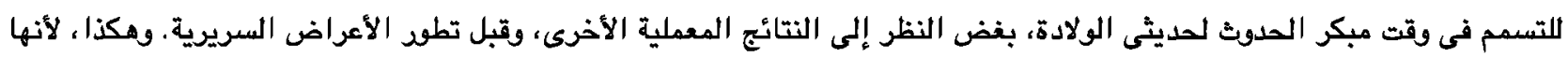

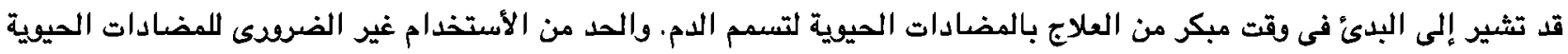

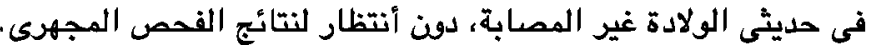

